quem queira discutir, vou submeter a votação as conclusões, que peço ao sr. Secretário ler.

O SR. SECRETÁRIO - (lendo) :

I - A duplicata é título causal, no sentido de que se deve prender a uma relação fundamental típica: a compra-e-venda mercantil.

II - A duplicata é título formal, suscetível de engendrar obrigações abstratas.

III - A falta de efeiva entrega de mercadorias não invalida a duplicata: é mera condição de irregularidade.

IV - 0 possuidor deve, obrigatòriamente, protestar a duplicata por falta de aceite, a fim de garantir o direito de regresso contra emitente e endossador.

.V - A sanção, de ordem privada, pela falta do aceite, é a perda do prazo de vencimento, em vista de que a obrigação oriunda do contrato de compra e venda se torna desde logo exigível.

VI - O comprador, não tendo reconhecido a exatidão do título, não se obriga por via de duplicata, que, de si só, não legitima ação, executiva ou não.

O SR. PRESIDENTE - Os srs. Congressistas que aprovarem a tese queiram manter-se sentados. (Pausa.) Aprovada. dente.

- Pela ordem, sr. Presi-

Aprovo tôdas as conclusões, apenas ressalvando meu ponto de vista com relação às duplicatas, porque realmente falta qualquer cousa, como tive ocasião de expor.

\section{CONTRA QUEM DEVE SER PROTESTADO O TÍTULO CAMBIAL}

\section{Oscar Martins Gomes} Catedrático de Direito Internacional Privado da Uni-
versidade do Paraná.

1 - Assunto gerador de dúvidas, ocasionando, freqüentemente, na prática cotidiana, erros e inconveniências, quer entre portadores de títulos cambiais, quer da parte de serventuários, é êsse de saber contra quem devem ser protestados os títulos cambiais, se sòmente contra o sacado ou o aceitante, ou se deve o protesto estender-se tembém ao sacador, aos endossantes e aos avalistas.

2 - $\mathrm{O}$ conceito do protesto e um melhor conhecimento das razões que o explicam esclarecerão o tema. Eis, a propósito, a lição do eminente comercialista CARVALHO DE MENDONÇA:

"O protesto, para os efeitos cambiais, é a formalidade extra-judicial, mas solene, destinada a servir de prova da apresentação da letra de câmbio, no tempo devido, para o aceite e para o pagamento, não tendo o portador, apesar de sua diligência, obtido êste ou aquêle.

Êle se justifica pela necessidade de ser oferecida aos obrigados em via de regresso prova segura e, ao mesmo tempo, simples e uniforme, de qualquer dêsses fatos, que efetivam a sua responsabilidade.

$O$ protesto cambial vem assim a constituir elemento fundamental, para o exercício do direito de regresso. Sem êle não é possível ao possuidor da letra de câmbio exercer êsse direito contra os coobrigados regressivos e nem a qualquer dêstes, oportunamente, contra os seus antecessores." (Trat. de Dir. Com. Bras. vol. V, 2. ${ }^{\text {a }}$ parte, ns. 870 e 871 ).

3 - As formalidades com que o protesto deve ser tirado e seus efeitos vêm expressos nos arts. 28 e 32 da lei cambial (n. ${ }^{\circ} 2.044$, de 31 de dezembro de 1908). Ali se declara que o instrumento de protesto deve conter, entre outros requisitos, "a certidão da inti- 
mação ao sacado ou ao aceitante." (art. 29, n. ${ }^{\circ}$ III), ou "de não haver sido encontrada ou de ser desconhecida a pessoa indicada para aceitar ou pagar (art. 29, n. ${ }^{\circ}$ IV).

Em face do art. 30 da mencionada lei, ao portador é que compete dar aviso do protesto ao último endossador, dentro de dois dias, contados do instrumento do protesto, quando declarado no título o domicílio do mesmo.

E o art. 32 é terminante ao dispor que "o portador que não tira, ern tempo útil e forma regular, o instrumento de protesto da letra, perde o direito de regresso contra o sacador, endossadores e avalistas.

Aquêle citado comercialista entende mesmo que o protesto é uma providência instituída mais em beneficio dos coobrigados do que do próprio portadior da letra de câmbio, porque denuncia a mora do obrigado e dá a conhecer a "cada um dos devedores de regresso que surgiu a sua responsabilidade e assim, sem surprêsa, permitir-lhes preparar a soma para o pagamento da letra, poupando despesas com a ação cambial ou o ressaque" (ob. cit., ns. 871 e 889).

4 - De tôda oportunidade é a decisão proferida pelo Tribunal de Minas Gerais e assim resumida: "Não é necessário que o protesto por não pagamento contenha a certidão de intimação a todos os coobrigados. Ao aceitante ou emitente da letra ou da promissória, é que deve ser intimado o protesto." (Brasil-Acórdãos, vol. X, n. ${ }^{\circ}$ 26.215, ac. de 20/1/17).

Também o Tribunal de Pernambuco, em acórdão de $17 \mathrm{de}$ dezembro de 1937, decidiu que o protesto "basta ser notificado ao obrigado principal, valendo a intimação ou notificação para a conservação dos direitos regressivos contra os coobrigados." (Rv. For. vol. 75 , pg. 366).

5 - As normas relativas ao protesto da letra de câmbio são aplicáveis, com as modificações necessárias, à nota promissória, aquiparado o emitente desta ao aceitante daquela (lei n. ${ }^{\circ} 2.044$, art. 56), e, com as alterações expressas, à duplicata de fatura (lei n. ${ }^{\circ} 187$, de março de 1936 art. 20 e 23), na qual o comprador se assemelha ao sacado, ou ao aceitante da letra.

Não se cogita do protesto especial para efeito de falência (art. 11 da lei n. ${ }^{\circ}$ 5.746, de 9/12/1929).

MAGARINOS TÔRRES, com abundância de argumentos e. apoiado em CARVALHO DE MENDONCA e PAULO DE LACERDA, sustenta idéia, aliás vencedora, sem maior controvérsia, de que o protesto não deve ser intimado ao sacador, endossadores $e$ avalistas, já porque a lei tal não determinou, impondo sòmente, sob pena de nulidade, a intimação do primeiro obrigado, já porque residindo muitas vêzes os coobrigados em praças diferentes impossível e tornaria a apresentação do título a todos ao mesmo tempo, a fim de não perder o portador o direito regressivo. ("Nota Promissória", 4. ${ }^{\text {a }}$ edição, ns. 150 e 216 e notas).

6- A Associação Bancária do Rio de Janeiro reclamou, há muitos anos, contra a praxe seguida pelos oficiais de protesto de letras, que avisavam, além do sacado ou aceitante, os endossadores $e$ outros coobrigados, por meio de cartas e editais.

CARVALHO DE MENDONÇA, respeitada autoridade na matéria, emitiu então um parecer, datado de 23 de junho de 1925, dizendo ser "justíssima a reclamação sôbre a irregularidade que se tem infiltrado nos protestos", explicando que do protesto deve ser intimado apenas o sacado ou o aceitante, e acrescenta: "Os endossadores não são intimados pelo oficial público, nem pessoalmente nem pela imprensa".

Mais tarde, êsse acatado comercialista, em novo parecer de 25 de novembro de 1926, reportando-se ao anterior, escreveu: "A lei n. ${ }^{\circ}$ 2.044, no art. 29, assinala as menções que deve conter o protesto e daí se vê que são apenas notificados para aceitar ou pagar o sacado ou aceitante. Ante tão claros princípios não se pode compreender como se estabeleceu a praxe ilegal de tirar o protesto contra outros coobrigados. - Contra esta corruptela já elaborei o parecer de 25 de junho de 1925, cuja cópia .junto ao presente."

Esses pareceres se encontram publicados sob nrs. 58 e 82 no volume de Pareceres de Carvalho de Mendonça, edição do Banco do Brasil, 1941.

Quanto ao avalista do aceitante da letra de câmbio ou do emitente da nota promissória, a circunstância de não se livrar da responsabilidade pela falta do protesto do título ainda melhor explica porque não há necessidade de intimar-lhe o protesto, quando tirado.

7 - O professor JOÃO EUNÁPIO BORGES, em judicioso estudo publicado na Revista Forense, vol. 24, de 1949, págs. 605 a 608 , após aludir a equívocos e a superstições em matéria de protesto, mostra que, de acôrdo com a lei e a doutrina, a intimação do protesto deve ser feita "apenas ao sacado ou aceitante na letra de câmbio ou ao emitente na nota promissória." Escreve ainda o douto jurista: "É êrro, pois, e grave, pelo qual o oficial do protesto pode ser responsabilizado pelos danos a que der causa, o de se fazer a intimação para pagar, quase sempre por meio de editais publicados pela imprensa, a todos os coobrigados no título cambial. É êrro também muito comum darem os portadores instruções ao oficial no sentido de ser feito o protesto apenas contra certos coobrigados, excluindo êsse ou aquêle. São recomendações inúteis e supérfluas $O$ protesto não se faz, em rigor, contra ninguém." Também WHI- 
"TAKER, na sua compulsada obra "Letra de Câmbio", 3. a edição, pág. 229, explica que, no protesto só ao sacado se intima, tenha ou não aceitado a letra, e acrescenta: "A notificação aos coobrigados subsidiários (sacador e endossante) não incumbe ao oficial de protestos, mas ao próprio portador, sob pena de responder por perdas "e danos."

8 - $\mathrm{O}$ instituto do protesto ressente-se, em verdade, de falhas, que precisam de ser corrigidas mediante lei especial, mantida embora a lei cambial atual, ou adotada a Lei Uniforme aprovada na conferência internacional de Genebra, de acôrdo com as convenções ali assinadas em 7 de junho de 1930 e relativas à letra de câmbio e à nota promissória, inclusive as reservas permitidas, bem assim a alguns conflitos que ainda possam surgir a respeito e ao impôsto do sêlo devido por tais títulos.

A suscinta apreciação seguinte põe em destaque os pontos capitais do instituto no âmbito do direito internacional privado.

9 - O Tratado de Montevidéu de 1889 e o Código Bustamante de 1928, arts. 26 e 263 respectivamente, na enumeração dos atos subordinados à regra locus regit actum, incluíram também o protesto, com referência especial, porém, só à sua forma, porque outro dispositivo do citado Código (art. 270) determinou expressamente que os prazos e formalidades para o aceite, pagamento e protesto submetem-se à lei local.

A lei brasileira (n. ${ }^{\circ} 2.044$, art. 47 ), num preceito que é de direito internacional privado, manda regular pela lei do lugar onde a obrigação foi firmada a substância, os efeitos, a forma extrínseca e os meios de prova da obrigação cambial, sem referência ao protesto, a rigor tirado no lugar da aceitação ou no do pagamento, quando êste ou aquelha falham, pois o protesto visa documentar a apresentação do título para aceite ou pagamento.

A convenção sôbre conflitos votada em Genebra apenas dispôs acêrca da forma $e$ dos prazos do protesto e da forma dos atos necessários ao exercício e à conservação dos direitos, mandando que sejam regulados, os prazos e a forma, pela lei do Estado onde fôr tirado o protesto ou realizado o ato indicado.

Eis o texto original:

Art. $8 .^{\circ}$ - La forme e les délais du protêt, ainsi que la forme des autres actes nécessaires á l'exercice ou á la conservation des droits en matiére de lettre de change ou de billet á ordre, sont réglés par les lois $d u$ pays sur le territoire duquel doit être dressé le protêt ou passé l'acte en question."
Pela aplicação da regra locus regit actum, as notificações, os avisos acauteladores, o protesto, assim como os prazos dêste, obedecem à lei do lugar onde devem êsses atos ser levados a efeito. São providências necessárias ao exercício do direito regressivo, competindo ao julgador verificar se a lei estrangeira foi devidamente aplicada, em cada caso.

10 - J. PERCEROU e J. BOUTERON demonstram que a contradição que se possa enxergar entre o art. $80^{\circ}$ e o art. $50^{\circ} \mathrm{da}$ Convenção é apenas aparente, pois êste é extremamente limitado no seu objeto, visando só os prazos do exercício da ação de regresso, para os quais foi adotada a lei do lugar da criação do título, e acrescenta: "L'article 8 ao contraire, qui a une portée beaucoup plus large, n'est que l'aplication de la régle locus regit actum pour toutes les autres diligences qui, dans l'exercice du recours, ne sont pas les délais euxmêms de l'exercice de ce recours. (Lettre de Change etc., Paris, 1937, pag. 201).

11 - PONTES DE MIRANDA levanta interessante questão: "Há a cláusula "sem protesto", empregada pelo sacador, ou pelo endossante, e discute-se qual a lei que o regula, - a lei do Estado do pagamento do título cambial, a lei do Estado onde o protesto será necessário, ou a lei de cada obrigação para a persistência da qual seria de mister o protesto...... - Houve quem quisesse o estatuto do lugar em que se criou a cambial, com o que se obteria disciplina única. - ARRIGO CAVAGLIERI pugnou pela lei do Estado onde o legítimo possuidor do título cambial exigiu, inùtilmente, se bem que tempestivamente, o pagamento, ao obrigado principal........ - A Convenção de Genebra não anuiu em que o protesto dependesse da lei do lugar em que se devesse protestar o título, quanto à forma $e$ aos prazos. É muito diferente de ter deixado a tal lei dispensar o protesto ou não, ou não admitir ou proibir a cláusula "sem protesto". (Nota promissória, pág. 300).

12 - Em verdade, numa das reservas (art. $80^{\circ}$ ) que formam o anexo II da Convenção de Genebra contendo a Lei Uniforme, vem expressa a faculdade concedida aos Estados contratantes de prescreverem que os protestos que devem ser tirados no seu território possam ser substituídos por uma declaração datada e escrita sôbre a própria letra de câmbio e assinada pelo sacado, salvo no caso em que o sacador exija no texto da letra de câmbio um protesto por ato autêntico. Facultado ficou ainda aos Estados contratantes, pela mesma "reserva", prescrever que a citada declaração seja transcrita no registro público dentro do prazo fixado para o protesto.

Não há, pois, nas convenções genebresas admissão, como não há também proibição expressa, da cláusula "sem protesto". 
As reservas constituem derrogações às prescrições estabelecidas na lei comum, e as concernentes à matéria de protesto formam o maior número delas no citado anexo II, para uso de cada país na órbita da sua legislação interna. Daí os conflitos de leis, para a solução dos quais a Conferência de Genebra votou a Convenção aprópriada, como normas de direito positivo para os Estados que a retificaram e como normas de orientação doutrinária para os demais Estados.

13 - Num estudo comparativo, BAYALOVITCH acha o sistema anglo-americano superior ao sistema chamado continental (Lei Uniforme), sob diversos aspectos, entre os quais ó concernente à regulamentação das formalidades para a conservação ou o exercício dos direitos cambiais, principalmente na determinação da importância de cada uma delas. E diz: "La notification et le protêt du droit cambiaire anglo-americain ont une valeur respective exactement inverse de celle qui leu est attribuée par le droit dit continental. Les lois anglaise et americaine se sont plieés aux réalités de la pratique comerciale en reconnaissant comme une formalité indispensable la notification et en laissant um caractére facultatif á la formalité lourde e compliquée qu'est le protêt." (Le Droit Internationel du Change, Paris, 1935, (pág. 497).

14 - Seria de acolher uma inovação na atual lei cambial brasileira, independentemente de sua substituição integral por outra, visando apenas os meios tendentes a assegurar os direitos cambiais sem a necessidade exclusiva do protesto, como, ex., permitir a cláusula "sem protesto", a ser aposta pelo sacador ou pelo endossante, ou permitir uma declaração feita pelo sacado, ou aceitante, na letra de câmbio, ou pelo emitente, na nota promissória, não abolido protesto por ato solene e público, para quando o portador preferir essa forma.

15 - A explanação até aqui desenvolvida e os pontos de vista concomitantemente sustentados levam às seguintes

\section{O N C L U S Õ E S}

a) Em face do direito brasileiro vigente, o protesto, documentando de forma solene a apresentação do título cambial para aceite ou para pagamento, deve ser intimado apenas ao obrigado principal ou direto, ou sejam o sacado ou o aceitante, na letra de câmbio, ou o emitente, na nota promissória, sem que a singularidade da intimação deixe de surtir os efeitos próprios a êsse ato público, notadamente os concernentes a garantir o direito regressivo. b) É aconselhável, consoante se verifica em outras legislações, como a alemã, a suiça, a italiana, introduzir no direito brasileiro, independentemente de maior reforma da lei cambial, fórmulas sucedâneas do atual protesto, sem exclusão dêste, mas de modo a permitir a cláusula "sem protesto" no título ou a declaração formal nêle de recusa de aceite ou de pagamento, quando apresentado, produzindo os mesmos efeitos do protesto.

Curitiba, 31 de Julho de 1950.

\section{R E L A T Ó R I O}

\section{Relator: JOSÉ BAPTISTA NETO}

O Ilustrado Professor OSCAR MARTINS GOMES, Catedrático de Direito Internacional Privado da Faculdade de Direito do Paraná, contribui, para êste Congresso, com a concisa e bem elaborada tese de sua autoria, intitulada - CONTRA QUEM DEVE SER PROTESTADO O TÍTULO CAMBIAL.

Divisamos, no interessante trabalho do Prof. Martins Gomes, duas partes distintas. A primeira contém um estudo interpretativo da lei brasileira n. ${ }^{\circ} 2044$, de 31 de dezembro de 1908; ao passo que a segunda destina-se a fundamentar a sua proposição no sentido de ser alterada essa mesma lei.

Dividindo, no plano geral, o seu trabalho em quinze itens, dedicou os sete primeiros à primeira parte, que se enquadra perfeitamente na denominação da tese, uma vez que aí é que examina pròpriamente, "contra quem deve ser protestado o título cambial".

Começa por afirmar que se trata de assunto gerador de dúvidas e, assim, de erros e inconveniências, tanto por parte dos portadores dos títulos como de parte dos serventuários encarregados do protesto.

Passa, a seguir, a demonstrar que, do protesto, devem ser intimados apenas o sacado ou o aceitante da letra de câmbio e o emitente da nota promissória. Enuncia o conceito de protesto, afirmando ser o ato solene pelo qual fica documentada a apresentação do título para aceite ou para pagamento.

Citando dispositivos da lei 2044 e trazendo, em abono de sua tese, os ensinamentos de tratadistas, como Carvalho de Mendonça, Magarinos Tôrres, Paulo de Lacerda e Whitaker, a opinião do Prof. Ioão Eunápio Borges, bem como acórdãos dos Tribunais de Minas Gerais e de Pernambuco, - conclui que, do protesto, devem ser in- 
timados apenas o sacado ou o aceitante da letra de câmbio bem como o emitente da nota promissória, e que os avisos aos demais coobrigados (endossantes) devem ser dados pela parte interessada, nos têrmos da lei 2044, art. 30.

Tratando, nos itens n..$^{\circ} 8$ e seguintes, da segunda parte de sua tese, começa o autor por afirmar que o instituto do protesto ressente-se de falhas que necessitam de correção por lei especial, mantida embora a lei cambial atual, ou adotada a lei uniforme aprovada na Conferência Internacional de Genebra, de acôrdo com as convenções ali assinadas em 7 de junho de 1930.

Confronta, a seguir, o art. 26 do tratado de Montevidéu de 1889; os arts. 263 e 270 do Código Bustamante; o art. 47 da lei brasileira 2044, e o art. $8 .^{\circ}$ da Convenção sôbre Conflitos, adotada em Genebra, - assinalando que, na matéria atinente ao protesto, dispõe esta apenas quanto ao prazo e à forma, mandando que sejam regulados de conformidade com a lei do país onde deva ser lavrado o protesto.

Afirma que, "pela aplicação da regra locus regit actum, as notificações, os avisos acauteladores, o protesto, assim como os prazos dêste, obedecem à lei do lugar onde êsses atos devem ser levados a efeito." "São providências necessárias ao exercício do direito regressivo, competindo ao julgador verificar se a lei estrangeira foi devidamente aplicada, em cada caso" - diz o autor.

Traz, depois, a questão levantada por Pontes de Miranda, no sentido de se saber qual a lei aplicável quando, pelo sacador ou pelo endossante, fôr empregada a cláusula "sem protesto", - "se é a lei do Estado do pagamento, a lei do Estado onde o protesto será necessário ou a lei de cada obrigação para cuja persistência seria mister o protesto".

Cita a seguir o Anexo II, art. 8. ${ }^{\circ}$, à Convenção de Genebra, onde se faculta aos Estados contratantes a determinação de que os protestos a serem tirados em seu território possam ser substituídos por uma declaração escrita, datada e assinada pelo sacado, na própria letra de câmbio, da recusa do aceite ou do pagamento, salvo o caso em que o sacador exija, na própria letra de câmbio, o protesto por ato autêntico, e que, no mesmo artigo, ficou também facultado prescreverem, os mesmos Estados, que essa declaração seja transcrita no registro público. Esclarece, logo em seguida, que nas .convenções de Genebra, não há proibição nem admissão expressa da cláusula "sem protesto".

Lembra, também, que as leis inglêsa e norte-americana dispensam a formalidade do protesto, dando-lhe um caráter facultativo, embora reconheçam a notificacão como formalidade indispensável, transcrevendo o elogio que Bayalovich tece a êsse sistema.

Conclui que, na legislação brasileira, se deverá introduzir mo- dificações no sentido de ser permitida a cláusula "sem protesto", a ser aposta no título pelo sacador ou pelo endossante, ou permitir uma declaração feita pelo sacado ou aceitante da letra de câmbio, ou pelo emitente da nota promissória, no próprio título, da recusa do aceite ou do pagamento, mas não abolindo o protesto, por ato solene e público, quando o portador o preferir.

No desenvolver do seu trabalho, deixa o seu autor transparecer claramente a louvável intenção que o animou, no sentido de uniformizar a matéria no âmbito do Direito Internacional, o que conseguiria, entretanto, apenas se todos os países anuíssem na uniformização, ainda mais que a própria Convenção de Genebra, reconhecendo a existência de diversidade entre as legislações, ditou regras com a intenção de resolver os conflitos.

Com a devida vênia, porém, temos fortes reservas contra uma alteração que visasse permitir cláusulas no título cambiário, o que. viria certamente perturbar as suas excelentes condições de certeza, literalidade e fácil circulabilidade, conseguidas por uma lei que vigora há mais de quarenta anos, cujo rigor se manifesta, nesse sentido, ao considerar não escrita para os efeitos cambiais, até a cláusula. de juros.

Passamos, pois, a propor a aceitação das conclusões anexas.

\section{PARECER}

Conclui o relator com o ponto de vista de que deverá ser aprovada a $1 .^{a}$ conclusão da tese no sentido de que do protesto deve ser intimado apenas o obrigado principal pelo título cambiário, ou seja o emitente da nota promissória, ou em se tratando de letras. de câmbio, o sacado ou aceitante valendo a intimação suficientemente para o exercício do direito de regresso contra os demais coobrigados.

Quanto à segunda conclusão sugerida pelo autor, discorda o. relator com a devida vênia por não entender conveniente ou oportuna a adoção dos sucedâneos do protesto ou sejam a "cláusula sem protesto" ou a declaração formal no próprio título da recusa do. aceite ou do pagamento, pôsto que tais declarações viriam ferir os requisitos de certeza e segurança essenciais aos títulos creditórios. José Baptista Neto

Discutido e aprovado o parecer e recomendado a sua aprovação. ao plenário.

Pôrto Alegre, 17 de agôsto de 1950.

Antônio Martins Filho Paulo Barbosa Lessa 